\section{Understanding the breathing gas capacities (ratings) of escape respirators for mineworker use}

By R. Metzler, T. Rehak, J. Szalajda, R. Berry Ann

The following information will help workers understand the meaning of breathing gas capacity of a jointly approved National Institute for Occupational Safety and Health (NIOSH) and Mine Safety and Health Administration (MSHA) closed-circuit escape respirator (CCER). Understanding the uses and limitations of the CCER is important in planning for an escape during a mine emergency.

CCERs are known in the mining industry as self-contained self-rescuers (SCSR). All closed-circuit escape respirators contain a fixed quantity of oxygen. The new NIOSH/MSHA CCER standards upgraded the performance and design requirements of this type of respirator and established an oxygen capacity level for each CCER so that a purchaser can know how much oxygen it contains.

Under the old standard, CCERs were rated and labeled by duration specified in time intervals. It did not indicate the volume of oxygen that the CCER contained. The rated duration can be very misleading because the amount of oxygen needed to complete a successful escape varies both for each person and for each escape scenario.

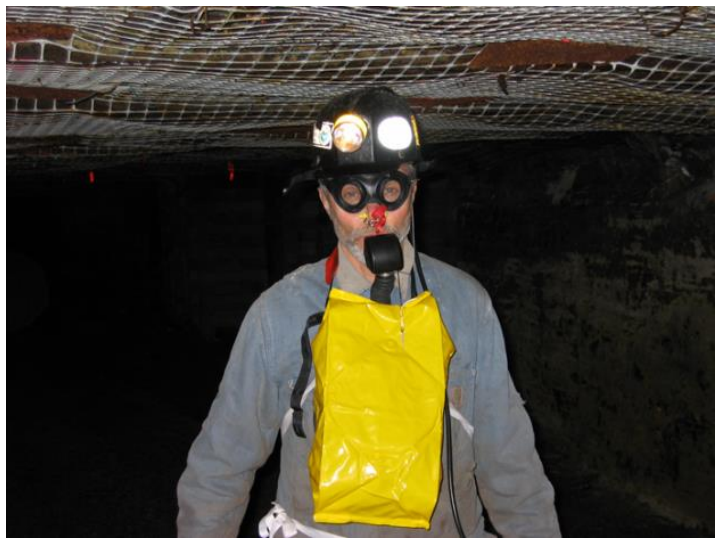

What is a CCER capacity rating?

A CCER is rated as CAP1, CAP2, or CAP3 depending on the volume of oxygen it will supply. Each level represents a minimum volume of breathing gas: CAP1: $20 \leq$ Liters $\leq$ 59; CAP2: $60 \leq$ Liters $\leq 79$; and CAP3: $\geq$ 80 Liters. An approved CCER with CAP3 rating provides at least the same amount of oxygen as previously required under the old standards for a unit rated 60minutes.

How much oxygen is needed to perform work?

When the human body performs any activity, it requires the consumption of oxygen from the air we breathe. The body metabolizes (or "consumes") oxygen even while a person is resting. A greater amount of oxygen is needed when the body's activity becomes more physically demanding. Table 1 shows the typical oxygen consumption required by a person weighing about 190 pounds for three types of physical activities.

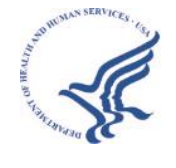


Table 1.

\begin{tabular}{|c|c|}
\hline Physical Activity $^{1}$ & $\begin{array}{l}\text { Oxygen } \\
\text { Consumption } 2 \\
\text { liters/min } \\
(\text { STPD) }\end{array}$ \\
\hline Resting & .4 \\
\hline $\begin{array}{l}\text { Very intense activity at } \\
\text { fast pace (working with } \\
\text { an axe, shoveling, } \\
\text { digging, climbing stairs) }\end{array}$ & 1.8 \\
\hline $\begin{array}{l}\text { Continuous work at } \\
\text { high intensity for } 15 \\
\text { minutes (crawling } \\
\text { under or climbing over } \\
\text { obstacles, removing } \\
\text { debris) }\end{array}$ & 2.9 \\
\hline
\end{tabular}

1. ISO/TS 16976-1 (2007) Technical Specification, Metabolic rates and respiratory flow rates, Table A.1, page 13.

2. ISO/TS 16976-1 (2007) Technical Specification, Metabolic rates and respiratory flow rates, Table 4, page 11.

3. Standard Temperature and Pressure, Dry

As indicated in Table 1, the harder someone works, the quicker the oxygen supplied by a CCER is consumed. The amount of oxygen required by a person to perform a given activity depends primarily on a person's body weight along with the additional weight being worn or carried (personal protective equipment, tools, etc.).

Does every individual require the same amount of oxygen to perform the same work?

More oxygen is required by a larger person than a smaller one for the same physical activity. Table 2 illustrates this point by showing the approximate oxygen consumption required by three different size (weight) persons performing the same physical activities. NIOSH and MSHA use a 1-hour Man Test 4 (a series of activities similar to the typical conditions faced in a mine escape) to approve CCERs for mining. This test is the basis of the comparison shown in Table2:

Table 2.

\begin{tabular}{|l|l|l|l|}
\hline $\begin{array}{l}\text { Exercise: } \\
\text { 1- hour Man } \\
\text { Test 4 }\end{array}$ & $\begin{array}{l}\text { Body } \\
\text { Size }^{1}\end{array}$ & $\begin{array}{l}\text { Body } \\
\text { Size }^{1}\end{array}$ & $\begin{array}{l}\text { Body } \\
\text { Size }^{1}\end{array}$ \\
\hline $\begin{array}{l}155 \\
\text { lbs }\end{array}$ & $\begin{array}{l}132 \\
\text { lbs }\end{array}$ \\
\hline $\begin{array}{l}\text { Oxygen } \\
\text { liters/hour } \\
\text { (STPD) }\end{array}$ & 81 & 71 & 65 \\
\hline
\end{tabular}

Data was extrapolated from ISO/TS 16976-1 (2007) Technical Specification, Metabolic rates and respiratory flow rates, pages 9-11, for 42CFR84, "Man test 4" metabolic requirements. 1. Body size indicate is an approximate weight.

As Table 2 indicates, the largest person requires approximately $25 \%$ more oxygen than the smallest one to complete the same physical activity.

In general, the more a person weighs, the more oxygen will be needed to complete the same activity. Body posture also affects the amount of oxygen consumed by an individual. For miners, the seam height of the mine can affect body posture and have an impact on the amount of oxygen needed to escape. As additional muscles are involved in an activity, more oxygen is needed to supply those muscles. Walking upright requires the least amount of oxygen while escaping followed by: walking bent at the head; walking bent at the waist; stooped walking; crawling; and the least efficient is duck walking.

How do I know which CCER capacity rating is right for my escape? A NIOSH/MSHA approved escape respirator must pass a rigorous battery of laboratory tests. In the previously
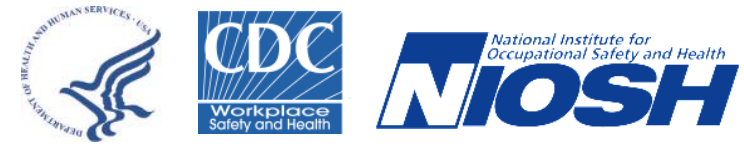
mentioned 1-hour Man Test 4, the CCER must provide at least 60 minutes of breathable air (80 liters) for a 192 pound person to complete the physical activities associated with the test.

As described above, oxygen consumption can vary depending primarily on a person's weight and the physical activity being performed. Furthermore, the total capacity for oxygen supply and carbon dioxide removal vary by respirator model. The NIOSH/MSHA requirement is a minimum standard, so depending on the size and type of respirator it could contain more oxygen than the amount needed to pass the test. Given these considerations, it is not possible to provide a specific duration rating that a CCER can supply breathable air for all individuals and under all conditions of use.

Oxygen consumption can, however, be estimated for a person based on his body size and physical activity. Therefore, knowing the oxygen capacity rating of a CCER, as explained above, provides useful information to assure an adequate supply of oxygen is available to meet the amount estimated for the person to complete specific physical activities. Together with effective training and trial escapes, a CCER with the proper oxygen capacity can be selected to meet the estimated needs for an effective escape.

With proper practice, routine training, and effective planning, an individual can become familiar with the performance of a CCER.
In conclusion, during an emergency, users must be confident that the CCER selected can provide enough oxygen to get them to a safe location. One way to determine the capacity level required by all individuals is to have the heaviest person wear regular work clothing and equipment, don the respirator, and travel the escape route from the deepest point of penetration in the mine to a point of safety. If the respirator does not have enough oxygen to enable this individual to execute a successful escape, then a CCER with a greater oxygen capacity should be selected, or else more respirators will need to be cached along escape ways.

Authors:

Richard W. Metzler, Engineer, National Institute for Occupational Safety and Health, National Personal Protective Technology Laboratory

Timothy Rehak, Engineer, National Institute for Occupational Safety and Health, National Personal Protective Technology Laboratory

Jonathan V. Szalajda, Engineer, National Institute for Occupational Safety and Health, National Personal Protective Technology Laboratory

Roland Berry Ann, Deputy Director, National Institute for Occupational Safety and Health, National Personal Protective Technology Laboratory
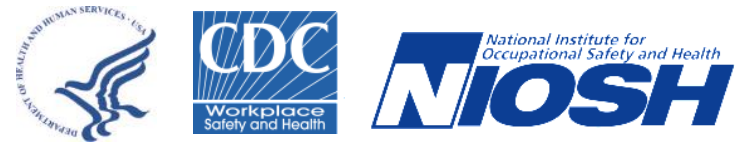
To receive NIOSH documents or more information about occupational safety and health topics, please contact NIOSH at

Telephone: 1-800-CDC-INFO (1-800-232-4636)

TTY: $1-888-232-6348$

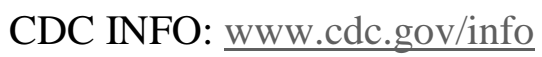

or visit the NIOSH Web site at www.cdc.gov/niosh

For a monthly update on news at NIOSH, subscribe to NIOSH eNews by visiting www.cdc.gov/niosh/eNews.

This document is in the public domain and may be freely copied or reprinted.

As part of the Centers for Disease Control and Prevention, NIOSH is the Federal agency responsible for conducting research and making recommendations to prevent work-related illnesses and injuries. Fact sheets describe how worker exposures to hazardous agents or activities can be reduced.

Mention of any company or product does not constitute endorsement by NIOSH. In addition, citations to Web sites external to NIOSH do not constitute NIOSH endorsement of the sponsoring organizations or their programs or products. Furthermore, NIOSH is not responsible for the content of these Web sites.

DHHS (NIOSH) Publication No. 2013-148

SAFER • HEALTHIER • PEOPLE ${ }^{\text {TM }}$

May 2013

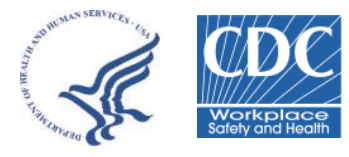

